DOI: 10.1590/1808-1657v77p6012010

\title{
CARACTERIZAÇÃO EPIDEMIOLÓGICA DA RAIVA BOVINA NO \\ ESTADO DE MATO GROSSO, BRASIL, NO PERÍODO DE 1996 A 2006
}

\author{
G.C.A. Matta ${ }^{*}$, D.L.P. Nociti, ${ }^{1}$ A.A.B. Carvalho ${ }^{2}$, R.P. Nociti², S.I. Samara ${ }^{2}$
}

${ }^{1}$ Universidade Federal de Mato Grosso, Faculdade de Agronomia e Medicina Veterinária, Av. Fernando Correa da Costa, s/no, CEP 78060-900, Cuiabá, MT, Brasil. E-mail: giovana.almeida@agricultura.gov.br

\section{RESUMO}

Um levantamento epidemiológico de todos os casos de raiva bovina ocorridos no Estado de Mato Grosso durante os anos de 1996 a 2006 foi realizado pela análise da curva epidêmica, por meio do cálculo do somatório, média, desvio padrão, valores máximos e mínimos da ocorrência de casos de raiva nos três ecossistemas; análise estatística entre o efetivo bovino nos três biomas do estado e o número de casos de raiva bovina; a distribuição sazonal e a situação da doença no estado em relação ao panorama nacional. Para organização dos dados, levou-se em consideração o mês e o ano de ocorrência da raiva e a região geográfica de origem do material. Os diferentes municípios envolvidos foram classificados conforme sua localização nas regiões de Cerrado, Pantanal e Amazônia. Constatou-se que a variação no número de casos positivos da enfermidade tem sido crescente nos últimos anos, sendo que o maior número de casos deu-se no bioma Cerrado, que apresentou uma tendência de aumento anual. A partir do ano de 2004, o ecossistema Cerrado passou da situação de enzootia para epizootia, ficando pois, evidente que o principal problema de raiva em bovinos no Estado de Mato Grosso está situado no bioma Cerrado.

PALAVRAS-CHAVE: Raiva, bovinos, epidemiologia, biomas, Mato Grosso.

\section{ABSTRACT}

EPIDEMIOLOGICAL CHARACTERIZATION OF BOVINE RABIES IN THE STATE OF MATO GROSSO, BRASIL, IN THE PERIOD FROM 1996 TO 2006. An epidemiological survey of all cases of bovine rabies that occurred in Mato Grosso, Brazil, during the years 1996 to 2006 was conducted by way of the analysis of the epidemic curve, by calculating the sum, average, standard deviation, maximum and minimum values of the occurrence of rabies in three ecosystems; statistical analysis between the actual cattle in the three biomes of the state and the number of cases of rabies cattle; and the seasonal distribution and disease situation in the state in relation to the national scene. The data were organized by taking into account the month and year of occurrence of rabies and the geographic region of the origin of the material. The different cities involved were classified according to their location in regions of Cerrado, the Pantanal and the Amazon. It was found that the variation in the number of positive cases of the disease has been increasing in recent years, with the largest number of cases occurring in the Cerrado biome, which showed a trend of annual increase. Beginning in the year 2004 the Cerrado ecosystem passed from the situation of enzootic to epizootic, making it evident that the main bovine rabies problem in the state of Mato Grosso is situated in the Cerrado biome.

KEY WORDS: Rabies, cattle, epidemiology, biomes, Mato Grosso.

\section{INTRODUÇÃO}

A raiva, causada por um vírus RNA do gênero Lyssavirus, da família Rhabdoviridae, éuma das viroses mais importantes para a pecuária e para a saúde pública no Brasil. Está distribuída em quase todo o mundo, tanto nos animais domésticos, quanto em animais silvestres, que servem como reservatórios por longos períodos (ACHA; SZYFRES, 1986). No Brasil, a caracterização antigênica e genética de amostras de vírus da raiva tem possibilitado a diferenciação em pelo menos duas variantes: variante canina (variante 1) e variante de morcego hematófago Desmodus rotundus (variante3) (ITO, 2005). Dentre as espécies de morcegos hematófagos, o Desmodus rotundusé o mais abundante nas Américas, e tem sido considerado o maior responsável pela transmissão da raiva aos herbívoros (Belloto, 2001). Avila Pires (1965) citou

${ }^{2}$ Universidade Estadual Paulista, Faculdade de Ciências Agrárias e Veterinárias, Jaboticabal, SP, Brasil.

*Programa de Pós-Graduação em Medicina Veterinária, UFMG. 
que a doença já devia existir, de forma endêmica, entre os animais silvestres, em áreas recém-colonizadas. Mas as condições artificiais criadas pelo homem, os grandes rebanhosconcentradosemáreasreduzidasedesmatadas abriram caminho à possibilidade de surtos epizoóticos de grandes proporções entre os animais domésticos. No Brasil, a raiva dos herbívoros pode ser considerada endêmica e em graus diferenciados, de acordo com a região. Os principais fatores que contribuem para que a doença no Brasil se dissemine ainda de forma insidiosa e preocupante são: aumento da oferta de alimento, representado pelo significativo crescimento dos rebanhos; ocupação desordenada, caracterizada por macromodificações ambientais, como desmatamento, construção de rodovias e hidroelétricas, que alteraram o ambiente em que os morcegos viviam, obrigando-os a procurar novas áreas e outras fontes de alimentação; oferta de abrigos artificiais, representados pelas construções, como túneis, cisternas, casas abandonadas, bueiros, fornos de carvão desativados e outros (DELPIETRO, 2000); atuação insatisfatória, em alguns estados brasileiros, na execução do Programa Estadual de Controle da Raiva dos Herbívoros (BrasiL, 2005). Estima-se que, no Brasil, a raiva dos herbívoros cause um prejuízo direto de aproximadamente U\$ 25 milhões de dólares a cada ano, com morte de 40.000 bovinos e perdas indiretas de aproximadamente U\$32 milhões de dólares (КотАIт et al., 1998). O Estado de Mato Grosso possui área de
903.357,908 km², 141 municípios e três biomas: Cerrado, Pantanale Amazônia.Possuiomaior rebanhobovinodo país, com 26.208.468animais(INDEA-MT, 2007Dadosnão publicados).Porém, a epidemiologia da raiva bovina no Estado é praticamente desconhecida, devido à escassez de trabalhos sobre o assunto. O presente estudo teve como objetivo conhecer a distribuição sazonal da raiva bovina em Mato Grosso; a relação do efetivo bovino nos três biomas do estado com os casos de raiva bovina; e a situação da doença no estado em relação ao panorama nacional. O propósito do levantamento desses dados foi definir as características epidemiológicas da raiva bovina no Estado de Mato Grosso.

\section{MATERIAL E MÉTODOS}

Foram utilizadosos dados doLaboratório de Apoio à Saúde Animal (LASA), pertencente ao Instituto de Defesa Agropecuária de Mato Grosso (INDEA/MT), que recebe amostras de tecido encefálico de bovinos com suspeita clínica de raiva de todo o Estado. O métododiagnósticoutilizado, conformerecomendaçãoda Organização Mundial de Saúde, foi a técnica de Imunofluorescência Direta (IFD) com o uso de conjugada antirrábico policlonal marcado pelo isotiocionato de fluoresceína ea prova biológica deinoculaçãointracerebralemcamundongos(IIC)(DeAnetal.,1996; KOPROWSKI,
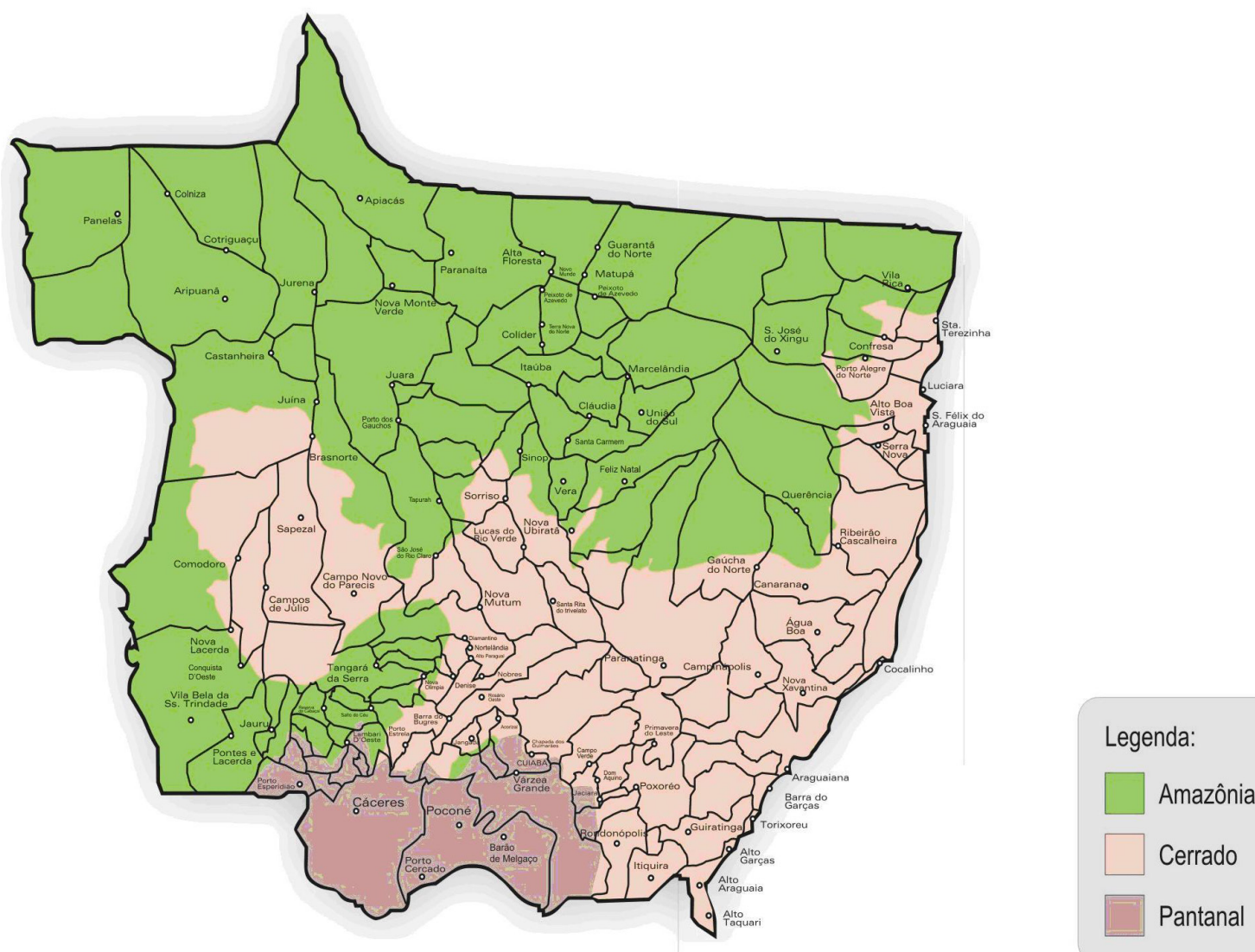

Fig. 1 - Distribuição dos biomas no estado de Mato Grosso. Adaptado de IBGE, 2008. 
1996). Para a análise dos dados foram consideradas 2.225amostras decérebros debovinosmachosefêmeas, diversasidadesecruzamentos raciais, provenientes de 136 municípios do Estado de Mato Grosso durante o período de 1996 a 2006. Para organização sua, levou-se em consideração o mês e o ano de ocorrência da raiva e a região geográfica de origem do material com base no mapa de divisão de biomas do IBGE (2008). Com a colaboração da SEPLAN (Secretaria de Planejamento do Estado de Mato Grosso), classificou-se os diferentes municípios envolvidos conforme sua localização nas regiões de Cerrado, Pantanal e Amazônia (Fig. 1). A análise da curva epidêmica foi feita por meio do cálculo do somatório, média, desvio padrão, valores máximos e mínimos da ocorrência de casos de raiva nos três ecossistemas do Estado de Mato Grosso, Brasil, entre os anos de 1996 a 2006 (JEKEL et al., 2005). A análise estatística entre o efetivo bovino e o número de casos de raiva bovina foi feita por meio do programa Mini tab 1.4, onde foi realizado o teste ANOVA, por meio de comparações entre o efetivo bovino do Cerrado, Amazônia e Pantanal e número de casos de raiva ocorridos no Cerrado, Amazônia e Pantanal. O nível de significância foi obtido através do teste de Tukey, com grau de confiabilidade de 5\%, comparando-se o efetivo bovino e o número de casos de raiva no Estado de Mato Grosso nos três biomas no período de 1996 a 2006 (JEKEL et al., 2005).

\section{RESULTADOS E DISCUSSÃO}

No contexto geral do período de 1996 a 2006, das 2.225 amostras com suspeitas clínicas, foram confirmadas laboratorialmente 745 (33,5\%) casos de raiva bovina em 95 (67,4\%) dos 141 municípios do Estado de Mato Grosso e 69,9\% sobre os 136 municípios que enviaram.

No período total do estudo, todos os estados do Brasil notificaram 14.100 casos, dos quais 745 (5,3\%) foram do Estado de Mato Grosso (Tabela 2), havendo um aumento na ocorrência dos casos de raiva.

NoEstado deMatoGrosso, houveum crescimento linear de casos notificados ao longo do período estudado. É possível que isto venha ocorrendo em razão da recente implantação do Programa Nacional de Controle da Raiva dos Herbívoros (PNCRH), executado pelo Ministério da Agricultura, Pecuária e Abastecimento (MAPA) em conjunto com órgãos de defesa animal estaduais. O PNCRH, que foi instituído no ano de 1966, estabelece suas ações visando o efetivo controle da ocorrência da raiva dos herbívoros no Brasil. Esse objetivo é alcançado por meio da vacinação estratégica de espécies suscetíveis e do controle populacional do seu principal transmissor, o D. rotundus, associados a outras medidas profiláticas e de vigilância. Várias unidades da
Federação possuem legislação própria que detalha as ações específicas sobre o programa em nível estadual, em apoio às normas federais. Estes estados desenvolvem programas organizados, com ações definidas quanto ao controle da espécie de morcego hematófago (D. rotundus), atividades educativas, diagnóstico laboratorial, estímulo à vacinação dos herbívoros domésticos, cadastramento de abrigos e vigilância epidemiológica. É necessário que essas ações ordenadas sejam ampliadas a todos os estados brasileiros (BRASIL, 2005). Porém, ações do programa só começaram a ser executadas a partir do ano 2000, e, apesar das ações adotadas, ainda existem falhas no programa, onde, devido à falta de pessoal e problemas de logística, muitas vezes não é possível executar de maneira adequada a vigilância epidemiológica nas áreas de foco e ainda encontrase em fase inicial o cadastramento de abrigos de morcegos nos municípios do estado. No entanto, a tendência é de que com as ações cada vez mais efetivas deste programa, o Estado de Mato Grosso tenha, no futuro, números de casos mais próximos da realidade, com o aumento de notificações, a partir da conscientização de produtores e efetiva fiscalização e, posteriormente, uma queda nos números de casos de raiva bovina, com a eficácia maior da execução do PNCRH. Com relação ao número de casos de raiva durante o período estudado em Mato Grosso, em vista ao tamanho do seu rebanho bovino, o número de casos está muito aquém da realidade. De acordo com KотAгт et al. (1998), para cada caso de raiva bovina notificado, cerca de 10 casos não o são. Esta assertiva corrobora com a situação atual da raiva bovina no Brasil, principalmente, no Estado de Mato Grosso, onde o elevado número de subnotificações compromete a eficácia do controle desta enfermidade. O Estado de Mato Grosso possuindo o maior rebanho bovino do País, uma área territorial de quase um milhão de quilômetros quadrados e três biomas diferenciados, deve ter a preocupação de incrementar e definir medidas profiláticas mais efetivas contra a raiva, principalmente, porque a velocidade de migração da raiva varia de 10 a 40 $\mathrm{km}$ por ano, segundo LORD (1988) e, ainda de acordo com TADDEI et al. (1991), a velocidade de migração pode alcançar até $200 \mathrm{~km} / \mathrm{ano}$. Sob outro prisma também devem ser avaliadas as condições ambientais favoráveis à manutenção do agente etiológico e disseminação do vírus pelos morcegos que encontram alimento em abundância, principalmente no gado bovino. Observando-se a ocorrência da raiva bovina conforme o ecossistema de origem, como pode ser visto na Tabela 3, o Cerrado é o bioma que oferece as melhores condições de disseminação da doença, possivelmente pelos fatores ambientais e climáticos que possibilitam meios propícios para manutenção dos morcegos, dentre eles o hematófago. No Brasil, 
o Cerrado ocupa uma área de 1,4 milhões de $\mathrm{km}^{2}$, sendo que, em Mato Grosso, a área ocupada pelo Cerrado é de aproximadamente $300 \mathrm{mil} \mathrm{km²}$, cerca de $34 \%$ do território estadual (FERREIRA, 2001).

O homem vem exercendo grande pressão sobre este bioma, sendo que não existem estimativas precisas de áreas convertidas à produção agropecuária. No entanto, é certo que as taxas de destruição aumentaram consideravelmente, principalmente, por meio da expansão da área cultivada de soja e o crescimento do rebanho bovino (FERREIRA, 2001). Por isso, não pode ser descartada a possibilidade desta biodiversidade tanto do Pantanal quanto da Amazônia albergar espécies diferentes das conhecidas até o momento como reservatório para manutenção do vírus da raiva. A Amazônia é o ecossistema de maior diversidade biológica do mundo, representando a mais extensa floresta tropical existente. É também o maior bioma brasileiro, sendo que, de seus aproximadamente 5,5 milhões de $\mathrm{km}^{2}$ de extensão em, torno de 3,3 milhões de $\mathrm{km}^{2}$ estão em território brasileiro e, desses, pelo menos $550 \mathrm{mil} \mathrm{km}^{2}$ estão dentro do Estado de Mato Grosso (54\% do território estadual). Juntamente com o Cerrado, é o bioma que apresenta as maiores taxas de conversão de florestas em uso agropecuário. Outras pressões significativas sobre os ecossistemas amazônicos estão representadas pela construção de barragens para produção de energia elétrica e pela indústria de extração madeireira (FERREIRA, 2001). Há possibilidade também de que a ocorrência de menor número de casos de raiva registrados nessa região deva-se à sua localização geográfica mais distante dos grandes centros, pela dificuldade de acesso devido às rodovias mal conservadas que em períodos de chuva tornam-se intransitáveis e também ao pequeno contingente de profissionais médicos veterinários nos municípios localizados nesse bioma. No bioma Cerrado, no período de 1996 a 2006, o número de casos de raiva foi crescente, onde a situação de enzootia nos anos de 1996 a 2003 passa para epizootia nos anos de 2004 a 2006 (Fig. 2). No bioma Pantanal (Fig. 3), neste mesmo período, o número de casos manteve-se na maior parte do tempo como enzootia, tendo picos de epizootia nos anos de 1998 a 1999 e no ano de 2002. No bioma Amazônia (Fig. 4), houve três momentos de epizootia, nos anos de 1997, 2001 e 2005. Nos demais anos a situação da raiva foi de enzootia. A tentativa de confrontar o número de bovinos com o número de casos de raiva e sua distribuição por municípios de cada ecossistema (Tabela 4) permite tão somente constatar, no mesmo período, que existe uma proporcionalidade direta entre os biomas com um efetivo maior de bovinos, com um maior percentual de ocorrência de casos de raiva.

Tabela 1 - Número de amostras positivas no diagnóstico da raiva bovina distribuídas em municípios que encaminharam amostras e municípios com bovinos positivos para raiva, Mato Grosso, 1996-2006.

\begin{tabular}{|c|c|c|c|c|c|c|c|}
\hline Ano & $\begin{array}{c}\text { Amostras } \\
\text { examinadas }\end{array}$ & Positivas & $\begin{array}{c}\% \text { de } \\
\text { amostras } \\
\text { positivas }\end{array}$ & $\begin{array}{c}\text { Municípios } \\
\text { que } \\
\text { enviaram } \\
\text { amostras }\end{array}$ & $\begin{array}{c}\text { Municípios } \\
\text { com } \\
\text { amostras } \\
\text { positivas }\end{array}$ & $\begin{array}{c}\% \\
\text { municípios } \\
\text { com casos } \\
\text { de raiva }^{\mathrm{a}}\end{array}$ & $\begin{array}{c}\text { \% de } \\
\text { municípios } \\
\text { com casos } \\
\text { de raiva no } \\
\text { Estado }^{b}\end{array}$ \\
\hline 1996 & 115 & 35 & 30,4 & 42 & 20 & 47,7 & 14,2 \\
\hline 1997 & 142 & 40 & 28,2 & 75 & 19 & 25,3 & 13,4 \\
\hline 1998 & 206 & 65 & 31,6 & 55 & 22 & 40,0 & 15,6 \\
\hline 1999 & 180 & 64 & 35,6 & 50 & 18 & 36,0 & 12,8 \\
\hline 2000 & 183 & 57 & 31,2 & 72 & 30 & 41,7 & 21,3 \\
\hline 2001 & 214 & 58 & 27,1 & 71 & 24 & 33,8 & 17,0 \\
\hline 2002 & 267 & 76 & 28,5 & 75 & 30 & 40,0 & 21,3 \\
\hline 2003 & 218 & 61 & 28,0 & 75 & 27 & 36,0 & 19,2 \\
\hline 2004 & 202 & 77 & 38,1 & 70 & 31 & 44,3 & 22,0 \\
\hline 2005 & 199 & 83 & 41,7 & 77 & 34 & 44,2 & 24,1 \\
\hline 2006 & 299 & 129 & 43,1 & 75 & 33 & 44,0 & 23,4 \\
\hline Total & 2.225 & 745 & 33,5 & 136 & 95 & 69,9 & 67,4 \\
\hline
\end{tabular}

a) dentre aqueles que enviaram amostras para exame.

b) dentre o total de municípios do Estado de Mato Grosso.

Tabela 2 - Casos de raiva bovina no Brasil e no Estado de Mato Grosso, 1996-2006.

\begin{tabular}{cccccccccccccc}
\hline & 1996 & 1997 & 1998 & 1999 & 2000 & 2001 & 2002 & 2003 & 2004 & 2005 & 2006 & Total \\
\hline Brasil & 1.083 & 1.124 & 1.150 & 1.469 & 1.633 & 1.434 & 1.377 & 1.307 & 1.192 & 1.152 & 1.179 & 14.100 \\
MT & 35 & 40 & 65 & 64 & 57 & 58 & 76 & 61 & 77 & 83 & 129 & 745 \\
\hline$\%$ & 3,2 & 3,6 & 5,7 & 4,4 & 3,5 & 4,0 & 5,5 & 4,7 & 6,5 & 7,2 & 10,9 & 5,3 \\
\hline
\end{tabular}


Tabela 3 - Quantidade e porcentagem de casos de raiva bovina distribuídos conforme bioma, Mato Grosso, Brasil, 1996-2006.

\begin{tabular}{ccccc}
\hline Ano & Cerrado & Pantanal & Amazônia & Total \\
\hline 1996 & $23(65,7 \%)$ & $8(22,9 \%)$ & $4(11,4 \%)$ & $35(4,7 \%)$ \\
1997 & $19(44,8 \%)$ & $10(26,3 \%)$ & $11(29 \%)$ & $40(5,4 \%)$ \\
1998 & $41(63,1 \%)$ & $18(27,7 \%)$ & $6(9,2 \%)$ & $65(8,7 \%)$ \\
1999 & $40(62,5 \%)$ & $20(31,2 \%)$ & $4(6,2 \%)$ & $64(8,6 \%)$ \\
2000 & $43(75,4 \%)$ & $9(15,8 \%)$ & $5(8,8 \%)$ & $57(7,6 \%)$ \\
2001 & $31(53,4 \%)$ & $16(27,6 \%)$ & $11(19,0 \%)$ & $58(7,8 \%)$ \\
2002 & $48(63,2 \%)$ & $19(25,0 \%)$ & $9(11,9 \%)$ & $76(10,2 \%)$ \\
2003 & $41(67,2 \%)$ & $14(23,0 \%)$ & $6(9,9 \%)$ & $61(8,2 \%)$ \\
2004 & $63(81,9 \%)$ & $11(14,2 \%)$ & $3(3,9 \%)$ & $77(10,3 \%)$ \\
2005 & $59(71,0 \%)$ & $13(15,7 \%)$ & $11(13,2 \%)$ & $83(11,1 \%)$ \\
2006 & $109(84,4 \%)$ & $15(11,7 \%)$ & $5(3,9 \%)$ & $129(17,4 \%)$ \\
\hline Total & $517(69,4 \%)$ & $153(20,5 \%)$ & $75(10,1 \%)$ & $745(100,0 \%)$ \\
\hline
\end{tabular}

Tabela 4 - Distribuição do efetivo bovino do Estado de Mato Grosso nos municípios caracterizados pelos três biomas, conforme a ocorrência da raiva bovina, entre os anos de 1996 e 2006.

\begin{tabular}{ccccc}
\hline Bioma & $\begin{array}{c}\text { Efetivo bovino } \\
\text { total }\end{array}$ & $\begin{array}{c}\text { Total de } \\
\text { municípios }\end{array}$ & $\begin{array}{c}\text { Municípios com } \\
\text { casos de raiva }\end{array}$ & $\begin{array}{c}\text { Efetivo bovino dos municípios } \\
\text { com casos de raiva }\end{array}$ \\
\hline Cerrado & 14.705 .695 & 95 & 65 & 10.849 .787 \\
Amazônia & 9.621 .830 & 42 & 23 & 6.652 .690 \\
Pantanal & 1.880 .943 & 4 & 4 & 1.880 .943 \\
\hline Total & 26.208 .468 & 141 & 92 & 19.383 .420 \\
\hline
\end{tabular}

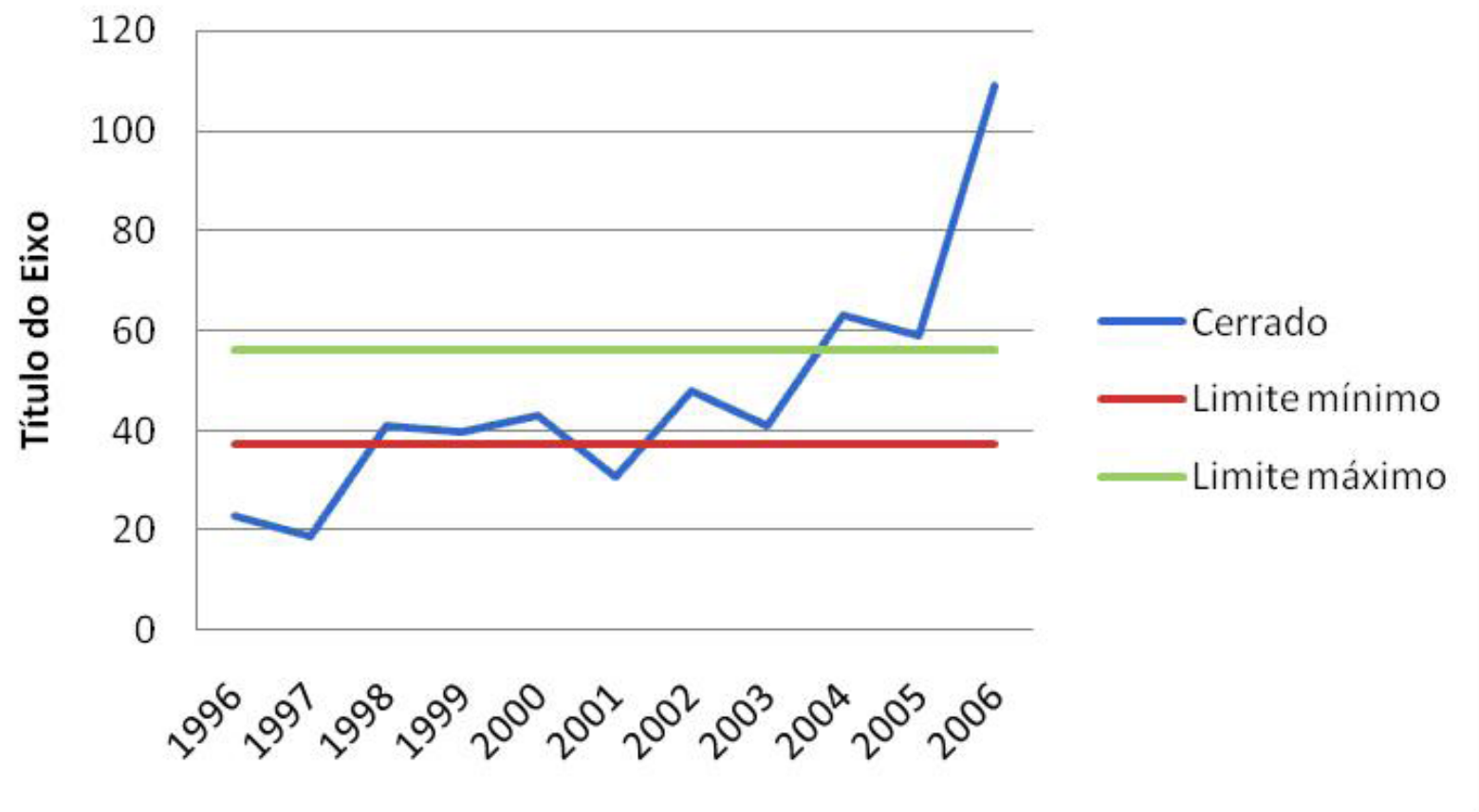

Fig. 2 - Curva epidêmica dos casos de raiva de 1996 a 2006 no cerrado. 


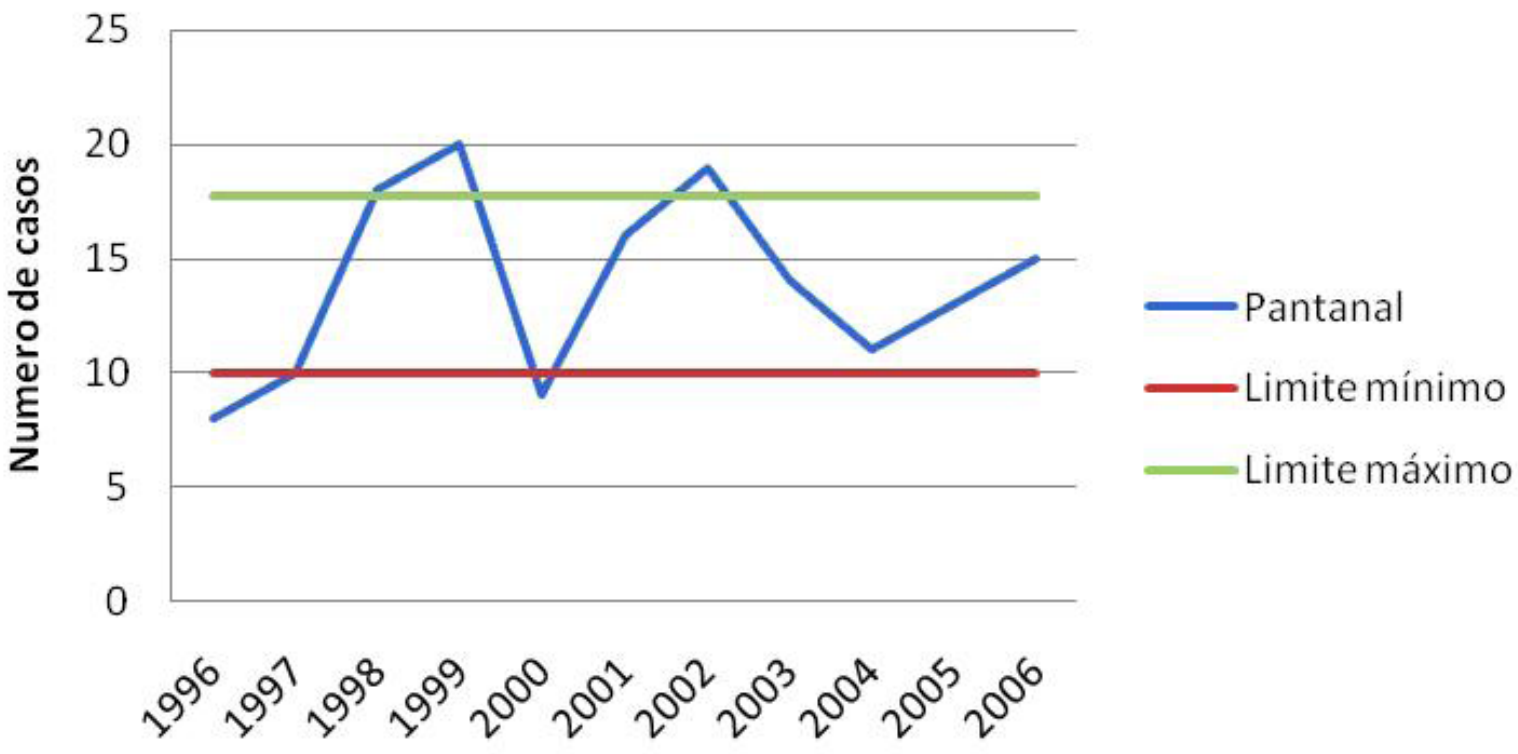

Fig. 3 - Curva epidêmica dos casos de raiva de 1996 a 2006 no Pantanal.

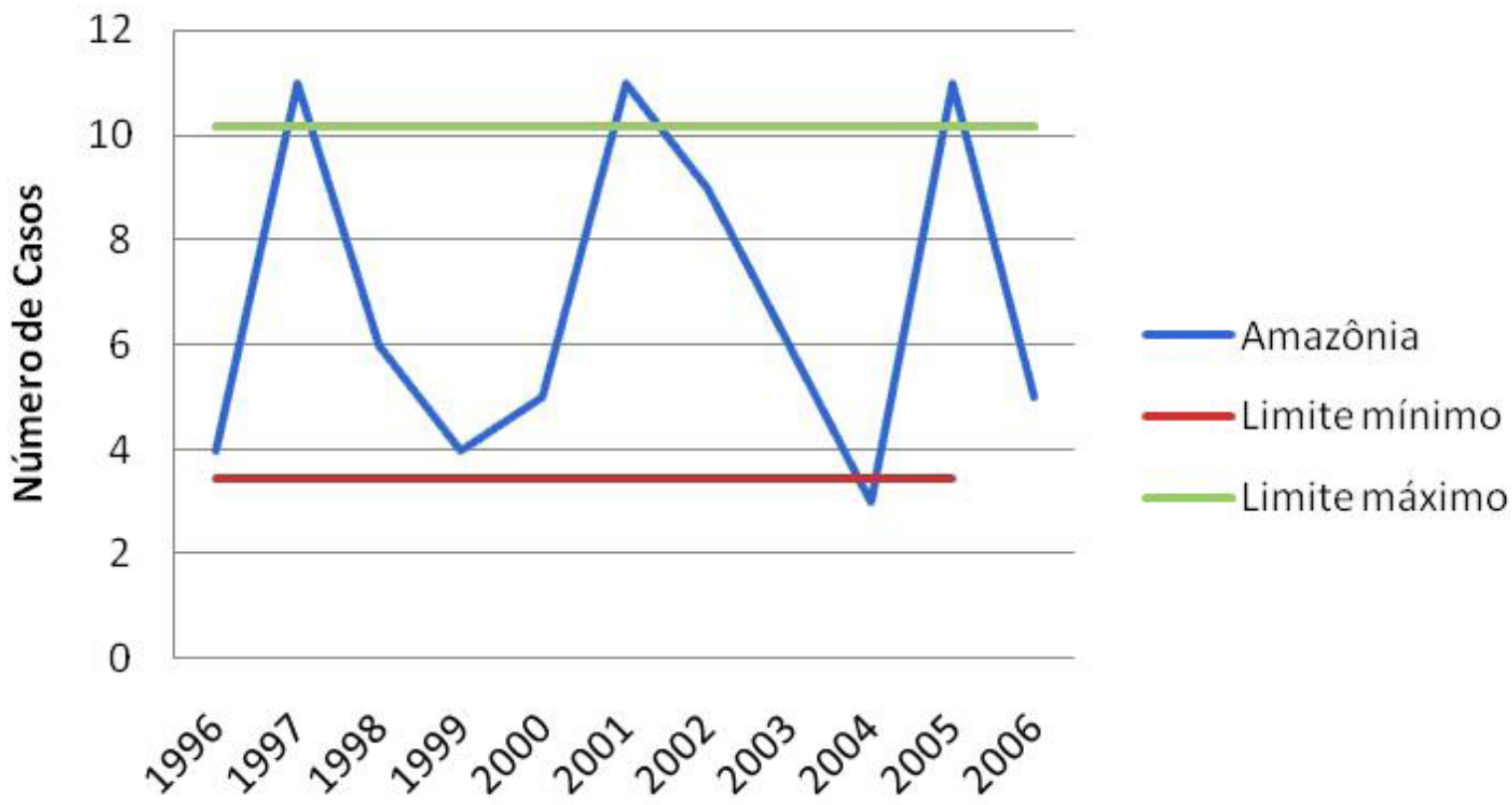

Fig. 4 - Curva epidêmica dos casos de raiva de 1996 a 2006 na Amazônia.

Comparando-se Pantanale Amazônia, com relação ao efetivo bovino e número de casos, houve significância, com $\mathrm{p}<0,05$. Já quando comparou-se o número de casos com o efetivo bovino dos municípios com casos de raiva, não houve significância, com $\mathrm{p}>0,05$. Na comparação entre Cerrado e Amazônia, houve significância em todas as comparações, sendo o valor de $\mathrm{p}<0,05$. Os mesmos resultados foram obtidos quando comparou-se Cerrado e Pantanal, sendo que para todas as comparações o valor de $p<0,05$, sendo portanto, significativo. Estes resultados estatísticos comprovam que o Cerrado, possuindo o maior efetivo bovino, possui também o maior número de casos de raiva emaior efetivo bovino com raiva queas regiões do
Pantanale Amazônia. Portanto, fica comprovadomais uma vez ser a região de Cerrado a área mais propícia à ocorrência de casos de raiva bovina. No contexto geral, a análise da sazonalidade da raiva, durante o período estudado em Mato Grosso, comprovou-se um aumento nos casos de raiva na estação seca, nos meses de julho e agosto, semelhante a Minas Gerais e São Paulo, onde a maior incidência é de abril a agosto (SILVA et al., 2001) e no Nordeste do Brasil, os meses de maior ocorrência vão de março a agosto (LiMA et al., 2005). No Mato Grosso do Sul, a época de maior incidência é o outono (abril a junho) (MORI et al., 2004). TADDEI etal.(1996) estudarama influência climática nos casos de raiva no Estado de São Paulo de 1981 a 1987. 
Assim, puderam observar uma maior ocorrência de raiva entre os meses de abril e junho.

\section{CONCLUSÃO}

No período estudado (1996 a 2006) constatou-se uma variação crescente no número de casos positivos de raiva bovina nos últimos anos, no Estado de Mato Grosso no qual constatou-se que a variação no número de casos positivos da enfermidade tem sido crescente nos últimos anos, sendo que o maior número de casos deu-se no Cerrado, que apresentou uma tendência de aumento anual, diferente do Pantanal e Amazônia, onde houve diminuição. A partir do ano de 2004, o ecossistema Cerrado passou da situação de enzootia para epizootia, ficando, pois, evidente que a situação problema no Estado de Mato Grosso se direciona mais para o bioma Cerrado, região onde deve ser priorizada a implantação de medidas sanitárias mais rígidas com relação ao controle da raiva bovina.

\section{REFERÊNCIAS}

ACHA, P.N.; SZYFRES, B. Zoonosis y enfermedades transmissibles communes al hombre y a los animales. 2.ed. Washington: Organización Panamericana de la Salud, 1986. p.502-526.

AVILA PIRES, F.D. de Biologia dos quirópteros e raiva dos herbívoros. Rio de Janeiro: Casa Valle, 1965. p.80-88. BELLOTO, A.J. Raiva transmitida por morcegos nas Américas: impacto na saúde pública e na produção. In: SEMINÁRIO INTERNACIONAL, MORCEGOS COMO TRANSMISSORES DA RAIVA, 2001, São Paulo, SP. Programas e Resumos. São Paulo, 2001. v.1, p.24-25.

BRASIL. Programa Nacional de Controle da Raiva dos Herbívoros. Controle da raiva dos herbívoros. Brasília: MAPA, 2005. 104p. (Manual Técnico).

DEAN, D.J.; ABELSETH, M.K.; ATANASIU, P. Fluorescent Antibody test. In: MESLIN, F. X.; KAPLAN, M.M.; KOPROWSKI, H. (Ed.). Laboratory techiniques in rabies. Geneva: World Health Organization, 1996. p.8895.

DELPIETRO, H.A. Aspectos econômicos y saniarios del problema de la rabia paralítica y de la agresión del vampiro. In: SEMINÁRIO INTERNACIONAL DA RAIVA, 2000, São Paulo, SP. Programas e Resumos: São Paulo: De Paula Print Artes Gráficas, 2000. v.1.

FERREIRA, J.C.V. Mato Grosso e seus municípios. 19.ed. Cuiabá: Secretaria de estado da Educação, 2001. 660p.
IBGE - INSTITUTO BRASILEIRO DE GEOGRAFIA E ESTATÍSTICA. Sistema IBGE de Recuperação Automática - SIDRA. Disponível em: <http:/ / mapas.ibge. gov.br/biomas2/viewer.htm>. Acesso em: 6 dez. 2008.

ITO, F.H. Programa Nacional do Controle da Raiva em Herbívoros: Revisão sobre raiva em herbívoros. 2005. Disponível em: <http://www.agricultura.gov.br>. Acesso em: 20 mai. 2007.

JEKEL, J.F.; KATZ, D.L..; ELMORE, J.G. Epidemiologia, bioestatística e medicina preventiva. 2.ed. Porto Alegre: Artmed, 2005. 432p.

KOPROWSKI, H. The mouse inoculation test. In: MESLIN, F.X.; KAPLAN, M.M.; KOPROWSKI, H. (Ed.). Laboratory techiniques in rabies. 4.ed. Geneva: World Health Organization, 1996. p.80-87.

KOTAIT. I. Controle da raiva dos herbívoros - vacinação: Past in Pasteur Informa, n.6, p.3, 2001.

KOTAIT, I.; GONÇALVES, C.A.; PERAS, N.F.; SOUZA, M.C.A.M.; TARQUETA, M.C. Profilaxia da raiva dos herbívoros. In: 1998. 15p. (Manuais, 1).

LIMA, E.F.; CORREA, F.R.; CASTRO, R.S.; GOMES, A.A.B.; LIMA, F.S. Sinais clínicos, distribuição das lesões no sistema nervoso e epidemiologia da raiva em herbívoros na região Nordeste do Brasil. Pesquisa Veterinária Brasileira, v.25, p.250-264, 2005.

LORD, R.D. Control of vampire bats. In: GREENHALL, A.M.; SCHIMIDT, U. (Ed.). Natural history of vampire bats. Florida: CRC Press, 1988. p.215-226.

MORI, A.E., LEMOS, R.A.A.; KADRI, A. Raiva. In: LEMOS, R.A.A.; KADRI, A.; KATAYAMA, K.A. (Ed.). Botulismo meningoencefalite por herpesvírus bovino tipo 5, poliencefalomalacia, raiva. Campo Grande: UFMS, 2004. p.63-86. (Série Qualificação Rural, 2).

SILVA, J.A.; MOREIRA, E.C.; HADDAD, J.P.A.; MODENA, C.M.; TUBALDINI, M.A.S. Distribuição temporal e espacial da raiva bovina em Minas Gerais, 1976-1997. Arquivo Brasileiro de Medicina Veterinária e Zootecnia, v.53, n.3, p.263-272, 2001.

TADDEI, V. A.; GONÇALVES, C. A.; TADEI, W. J.; KOTAIT, I.; ARIETA, C. Distribuição do morcego vampiro Desmodus rotundus (Chiroptera Phyl - Lostomidae) no Estado de São Paulo e a raiva dos animais domésticos. Campinas: CATI, 1991. 107p.

TADDEI, V.A. Sistemática de quirópteros. Boletim do Instituto Pasteur, v.1, p.3-15, 1996.

Recebido em 8/5/09

Aceito em $1 / 9 / 10$ 